\title{
Regulation of hyperactivation by PPP2 in hamster spermatozoa
}

\author{
Tatsuya Suzuki, Masakatsu Fujinoki ${ }^{1}$, Hiroaki Shibahara and Mitsuaki Suzuki \\ Department of Obstetrics and Gynecology, Jichi Medical University, 3311-1 Yakushiji, Shimotsuke-shi, \\ Tochigi 329-0498, Japan and ${ }^{1}$ Department of Physiology, School of Medicine, Dokkyo Medical University, \\ Tochigi 321-0293, Japan
}

Correspondence should be addressed to T Suzuki; Email: statsuya@jichi.ac.jp

\begin{abstract}
It has been widely accepted that serine/threonine protein phosphatases (PPPs) are associated with the regulation of sperm hyperactivation. In the present study, we examined the types of PPPs associated with the regulation of hamster sperm hyperactivation. Protein phosphatases PPP1CA, PPP1CC, PPP2, and PPP3 are present in hamster sperm. In the experiments using several inhibitors, sperm hyperactivation was enhanced when PPP2 was inhibited at least, although inhibition of PPP1 also enhanced sperm hyperactivation. Interestingly, sperm were hyperactivated after PPP2 became an inactive form. And then, PPP1CA became an active form after sperm were hyperactivated. It has also been widely accepted that tyrosine phosphorylation is closely associated with the regulation of sperm hyperactivation. When PPP2 was inhibited, tyrosine phosphorylation was not enhanced at all. On the other hand, inhibition of PPP1 enhanced tyrosine phosphorylation. From the results, it is likely that PPP2 is closely associated with the regulation of sperm hyperactivation, although it is not associated with the regulation of tyrosine phosphorylation.

Reproduction (2010) $139847-856$
\end{abstract}

\section{Introduction}

In mammals, ejaculated sperm and sperm obtained from caudal epididymis cannot fertilize a mature oocyte. They undergo complicated physiological and functional changes called capacitation in the female reproductive tract before fertilization (Chang 1951, Austin 1952). Capacitated sperm show an acrosome reaction in the head, and hyperactivation in the flagellum (Yanagimachi 1994). The acrosome reaction is a modified exocytotic event involving the acrosome (Yudine et al. 1988). The acrosome reaction is required for penetration of the zona pellucida and for sperm-egg plasma membrane fusion (Yanagimachi 1994). Hyperactivation is a specialized movement of the sperm flagellum that creates the propulsive force for penetration of the zona pellucida. Hyperactivated spermatozoa exhibit a high amplitude, asymmetrical beating pattern of the sperm flagellum (Morisawa 1994, Yanagimachi 1994, Suarez \& Ho 2003). Capacitation occurs in vitro in a specific culture solution containing albumin, bicarbonate, calcium, etc. Albumin removes cholesterol from the sperm plasma membrane to change the fluidity of the membrane (Langlais \& Roberts 1985). Bicarbonate increases intracellular $\mathrm{pH}$ and stimulates adenylate cyclase to increase cAMP (Okamura et al. 1985, Visconti et al. 1995, 1999). cAMP activates protein kinase A (PKA), and leads to protein serine/threonine phosphorylation and to sperm flagellar movement (Morisawa 1994, Visconti \& Kopf 1998, Si \& Okuno 1999a, Fujinoki et al. 2001 b, Breitbart 2002). In many cases (Morisawa 1994, Visconti \& Kopf 1998, Visconti et al. 1999, Fujinoki et al. 2001b), protein tyrosine phosphorylation also occurs in a cAMP-dependent manner. Calcium is involved in many intracellular signal transductions, such as regulation of adenylate cyclase, phosphodiesterase, and protein phosphorylation (Visconti \& Kopf 1998, Visconti et al. 1998, Si \& Okuno 1999a, Fujinoki et al. 2001a, Marín-Briggiler et al. 2005).

Recent understanding is that sperm hyperactivation is closely associated with protein tyrosine phosphorylation (Visconti et al. 1995, 1998, 1999, Visconti \& Kopf 1998, Fujinoki et al. 2001b, 2006, Jha \& Shivaji 2001, Marín-Briggiler et al. 2005, Noguchi et al. 2008). Moreover, it is suggested that protein serine/threonine phosphorylation is also associated with the regulation of hyperactivation (Naz 1999, Jha \& Shivaji 2002 b, Fujinoki et al. 2004, 2006). On the other hand, it has been suggested that protein dephosphorylation is also associated with the regulation of hyperactivation (Fujinoki et al. 2006). It has been suggested that inhibitors of protein phosphatase 1/2A (PPP1/PPP2), which are okadaic acid and calyculin A, enhanced hyperactivation and tyrosine 
phosphorylation in rodent sperm (Si \& Okuno 1999b, Goto \& Harayama 2009). Moreover, Furuya et al. $(1992,1993)$ reported that okadaic acid induced rapid acrosome reaction of mouse sperm, and that calyculin A induced rapid acrosome reaction and enhanced phosphorylation of phosphoproteins of human sperm. And then, Baker et al. $(2006,2009)$ reported that PKA-PPP1 signals regulated tyrosine phosphorylation associated with sperm capacitation. These reports support the hypothesis that PPP1/PPP2 exists in sperm, and exerts the regulation of acrosome reaction and hyperactivation. Other recent studies have reported that PPP1CC2 is involved in the regulation of motility activation and/or hyperactivation in mammalian sperm (Smith et al. 1996, Huang et al. 2005, Chakrabarti et al. 2007, Goto \& Harayama 2009). On the other hand, PPP3 (calcineurin) is also associated with the regulation of sperm motility and acrosome reaction (Tash et al. 1988, Tash \& Bracho 1994, Ashizawa et al. 2004).

Generally, protein phosphatases are classified into two families: serine/threonine phosphatases (PPPs) and phosphotyrosine phosphatases (Barford et al. 1998). PPPs include PPP1, PPP2, and PPP3. In mammals, PPP1 has four catalytic subunit isoforms (PPP1CA, PPP1CB, PPP1CC1 and PPP1CC2) encoded by three genes (PPP1CA, PPP1CB and PPP1CC), and many types of regulatory subunits (Ceulemans \& Bollen 2004). PPP1CC1 and PPP1CC2 are the alternatively spliced variants generated from a single gene. PPP2 consists of one catalytic subunit and two regulatory subunits known as A subunit and B subunit, and PPP3 consists of one catalytic subunit and three regulatory subunits known as B subunit, calmodulin, and A-kinase anchoring protein 79 (AKAP79; Barford et al. 1998). Both PPP1 and PPP2 are negatively regulated by phosphorylation of the catalytic subunit, and PPP3 is regulated by calcium. In the cell cycle, PPP1CA is regulated by cyclin-dependent kinase via phosphorylation of Thr-320 (Kwon et al. 1997, Ceulemans \& Bollen 2004). Activity of PPP2 is regulated by protein tyrosine kinase via phosphorylation of Tyr-307 and/or by autophosphorylation-activated protein kinase via phosphorylation of threonine residues (Chen et al. 1992, 1994, Guo \& Damuni 1993).

In the present study, we examined which protein phosphatases are associated with the regulation and/or enhancement of hyperactivation and tyrosine phosphorylation using various protein phosphatase inhibitors. Furthermore, we also examined activities of PPP1 and PPP2.

\section{Results \\ PPPs present in hamster sperm}

Previous studies (Tash et al. 1988, Tash \& Bracho 1994, Smith et al. 1996, Si \& Okuno 1999b, Ashizawa et al. 2004, Huang et al. 2005, Chakrabarti et al. 2007,
Goto \& Harayama 2009) suggested that PPP1, PPP2, and PPP3 were associated with the regulation of sperm motility and hyperactivation. Moreover, PPP1CC was detected in sperm (Smith et al. 1996, Huang et al. 2005, Chakrabarti et al. 2007, Goto \& Harayama 2009). At first, we examined which PPPs are present in hamster sperm. Although PPP1 has three isoforms of catalytic subunit, such as PPP1CA, PPP1CB, and PPP1CC, their molecular weights are different. Because the molecular weights of PPP1CA, PPP1CB, and PPP1CC are 38, 36, and $35 \mathrm{kDa}$, they are recognized as different bands. Using specific antibodies against each PPP1, as shown in Fig. 1, lanes $\mathrm{c}-\mathrm{h}, \mathrm{PPP} 1 \mathrm{CA}$ and PPP1CC were detected in hamster sperm, and PPP1CB was not detected. As for PPP2 and PPP3, molecular weights of their catalytic subunits are 36/38 and $59 \mathrm{kDa}$ respectively. As shown in Fig. 1, lanes i-l, they were also detected in hamster sperm using specific antibodies against catalytic subunits of PPP2 and PPP3. But reaction of PPP3 was very weak. Moreover, PPP1CA, PPP2, and PPP3 were mainly detected from the urea extracts, which include sperm proteins without the fibrous sheath and nucleus (Fujinoki et al. 2004). On the other hand, PPP1CC was detected from both the urea extracts and the urea-thiourea extracts, which include fibrous sheath proteins (Fujinoki et al. 2004).

\section{Effects of inhibition of PPP1 and PPP2 on sperm hyperactivation}

Si \& Okuno (1999b) reported that $5 \mu$ M okadaic acid and $2 \mu \mathrm{M}$ calyculin A significantly enhanced sperm hyperactivation in hamsters. They also reported that over $80 \%$ of the sperm had become fully hyperactivated within 40 min when $5 \mu \mathrm{M}$ okadaic acid and $2 \mu \mathrm{M}$ calyculin A were added to the modified Tyrode's albumin lactate pyruvate (mTALP) medium, although incubation for

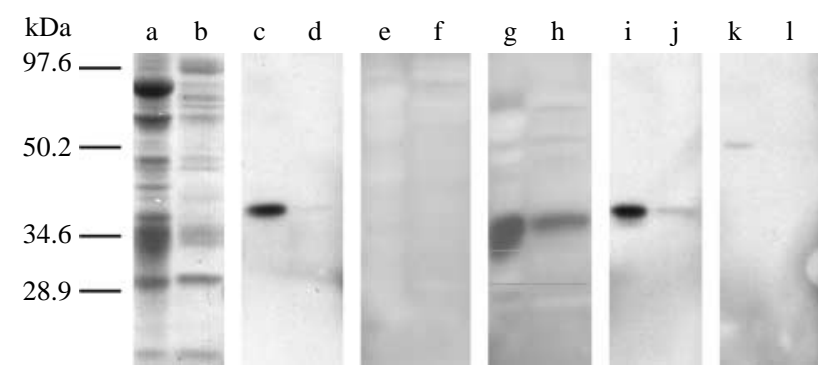

Figure 1 Detection of PPP1, PPP2, and PPP3 in hamster sperm. Twentymicroliter samples were applied for SDS-PAGE. Lanes a and b show blotting membrane stained by CBB. Lanes $\mathrm{c}$ and $\mathrm{d}$, lanes e and $\mathrm{f}$, lanes $\mathrm{g}$ and $\mathrm{h}$, lanes $\mathrm{i}$ and $\mathrm{j}$, and lanes $\mathrm{k}$ and $\mathrm{I}$ show detection of PPP1CA (1:1000 dilution), PPP1CB (1:200 dilution), PPP1CC (1:200 dilution), PPP2 (1:1000 dilution), and PPP3 (1:1000 dilution) using specific antibodies respectively. Lanes a, c, e, g, i, and k show results obtained through the urea extracts, and lanes $b, d, f, h, j$, and I show results obtained through the urea-thiourea extracts. Numbers on the left side of lane a indicate the molecular weights of the standards. 
about $3 \mathrm{~h}$ was required to produce hyperactivated motility in the mTALP medium alone. Because both PPP1 and PPP2 were inhibited by $5 \mu \mathrm{M}$ okadaic acid and $2 \mu \mathrm{M}$ calyculin $\mathrm{A}$ in the previous experiment (Si \& Okuno 1999b), we examined which PPPs are associated with the regulation of hyperactivation by using several concentrations of okadaic acid and calyculin A (okadaic acid: PPP1, IC $50=10-15 \mathrm{nM}$, PPP2, IC50 $=0.1 \mathrm{nM}$; calyculin A: PPP1, IC50 $=2 \mathrm{nM}$, PPP2, IC50 $=0.5-1.0 \mathrm{nM})$. As for the percentage of motile sperm, both okadaic acid and calyculin A did not exert an effect (data not shown). However, they significantly increased sperm hyperactivation (Fig. 2A and B). As shown in Fig. 2A, 10-500 nM okadaic acid significantly increased hyperactivation at incubation for $1.5 \mathrm{~h}$ (versus control and $0.1 \mathrm{nM}$ okadaic acid) and $2 \mathrm{~h}$ (versus control). At incubation for $2.5 \mathrm{~h}, 10$ and $50 \mathrm{nM}$ okadaic acid significantly increased hyperactivation compared with the control. But $500 \mathrm{nM}$ okadaic acid significantly decreased hyperactivation at incubation for $2.5 \mathrm{~h}$ (versus $0.1 \mathrm{nM}$ okadaic acid) and $4 \mathrm{~h}$ (versus control, and 0.1 and $10 \mathrm{nM}$ okadaic acid). Then, $0.1 \mathrm{nM}$ okadaic acid significantly increased hyperactivation at incubation for 2 and $2.5 \mathrm{~h}$ compared with the control. On the other hand, sperm hyperactivation was significantly increased at incubation for $0.5 \mathrm{~h}$ (versus control, and $0.5,2$, and $50 \mathrm{nM}$ calyculin $\mathrm{A}$ ), $1 \mathrm{~h}$ (versus control, and $0.5,2$, and $50 \mathrm{nM}$ calyculin $\mathrm{A}$ ), $1.5 \mathrm{~h}$ (versus control, and 0.5 and $2 \mathrm{nM}$ calyculin A), $2 \mathrm{~h}$ (versus control and $0.5 \mathrm{nM}$ calyculin $\mathrm{A}$ ), and $2.5 \mathrm{~h}$ (versus control) when $500 \mathrm{nM}$ calyculin A was added to the mTALP medium (Fig. 2B). Fifty-nanomolar calyculin A significantly increased hyperactivation at incubation for $1 \mathrm{~h}$ (versus control, and 0.5 and $2 \mathrm{nM}$ calyculin $\mathrm{A}$ ), $1.5 \mathrm{~h}$ (versus control, and 0.5 and $2 \mathrm{nM}$ calyculin $\mathrm{A}), 2 \mathrm{~h}$ (versus control), and $2.5 \mathrm{~h}$ (versus control). At incubation for $3 \mathrm{~h}, 50$ and $500 \mathrm{nM}$ calyculin A significantly decreased hyperactivation compared with $0.5 \mathrm{nM}$ calyculin A. However, 0.5 and $2 \mathrm{nM}$ calyculin A significantly increased hyperactivation at incubation for 1.5, 2, 2.5, and $3 \mathrm{~h}$ compared with the control, and did not affect hyperactivation at incubation for $1 \mathrm{~h}$.

In the next step, we used other inhibitors of PPPs such as tautomycin (PPP1, IC50 = $1 \mathrm{nM}$; PPP2, IC50 = $10 \mathrm{nM}$; Fig. 2C). As for the percentage of motile sperm, tautomycin did not exert an effect (data not shown). As shown in Fig. 2C, however, both 1 and $10 \mathrm{nM}$ tautomycin significantly increased sperm hyperactivation at incubation for 2 and $2.5 \mathrm{~h}$ compared with the control. Moreover, $1 \mathrm{nM}$ tautomycin also significantly increased hyperactivation at incubation for $3 \mathrm{~h}$ compared with the control.

\section{Effects of inhibition of PPP3 on sperm hyperactivation}

Because PPP3 is also associated with the regulation of sperm motility (Tash et al. 1988, Tash \& Bracho 1994) and acrosome reaction (Ashizawa et al. 2004),
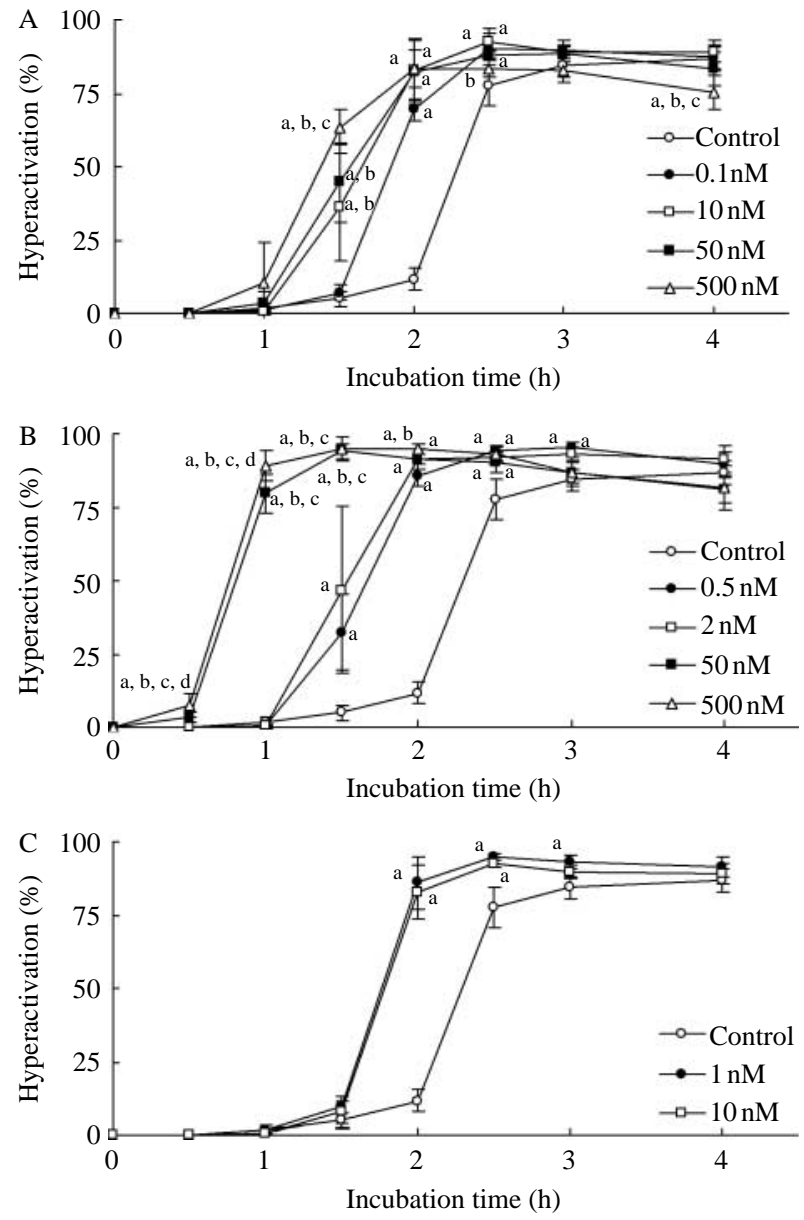

Figure 2 Effects of PPP1/PPP2 inhibitors on sperm hyperactivation. (A) Time- and dose-dependent changes in sperm hyperactivation with okadaic acid (mean \pm S.D., $n=4$ ). Sperm were incubated in modified TALP medium (control; open circles) or supplemented with $0.1 \mathrm{nM}$ (closed circles), $10 \mathrm{nM}$ (open squares), $50 \mathrm{nM}$ (closed squares), and $500 \mathrm{nM}$ (open triangles) okadaic acid. ' $a$ ' indicates a significant difference compared with the control $(P<0.05)$. ' $b$ ' indicates a significant difference compared with $0.1 \mathrm{nM}$ okadaic acid $(P<0.05)$. ' $C$ ' indicates a significant difference compared with $10 \mathrm{nM}$ okadaic acid $(P<0.05)$. (B) Time- and dose-dependent changes in sperm hyperactivation with calyculin A (mean \pm s.D., $n=4$ ). Sperm were incubated in modified TALP medium (control; open circles) or supplemented with $0.5 \mathrm{nM}$ (closed circles), $2 \mathrm{nM}$ (open squares), $50 \mathrm{nM}$ (closed squares), and $500 \mathrm{nM}$ (open triangles) calyculin A. ' $a$ ' indicates a significant difference compared with the control $(P<0.05)$. ' $\mathrm{b}$ ' indicates a significant difference compared with $0.5 \mathrm{nM}$ calyculin $\mathrm{A}(P<0.05)$. ' $\mathrm{C}$ ' indicates a significant difference compared with $2 \mathrm{nM}$ calyculin $\mathrm{A}(P<0.05)$. ' $\mathrm{d}$ ' indicates a significant difference compared with $50 \mathrm{nM}$ calyculin $\mathrm{A}(P<0.05)$. (C) Effects of tautomycin on hamster sperm hyperactivation (mean \pm s.D., $n=4$ ). Sperm were incubated in modified TALP medium (control; open circles) or supplemented with $1 \mathrm{nM}$ (closed circles) and $10 \mathrm{nM}$ (open squares) tautomycin. ' $a$ ' indicates a significant difference compared with the control $(P<0.05)$.

we examined whether PPP3 affected the regulation of hyperactivation using deltamethrin $(\mathrm{IC} 50=100 \mathrm{pM})$ and fenvalerate (IC50 $=2-4 \mathrm{nM}$; Fig. 3). When $100 \mathrm{pM}$ to $1 \mu \mathrm{M}$ deltamethrin was added to the mTALP medium, 

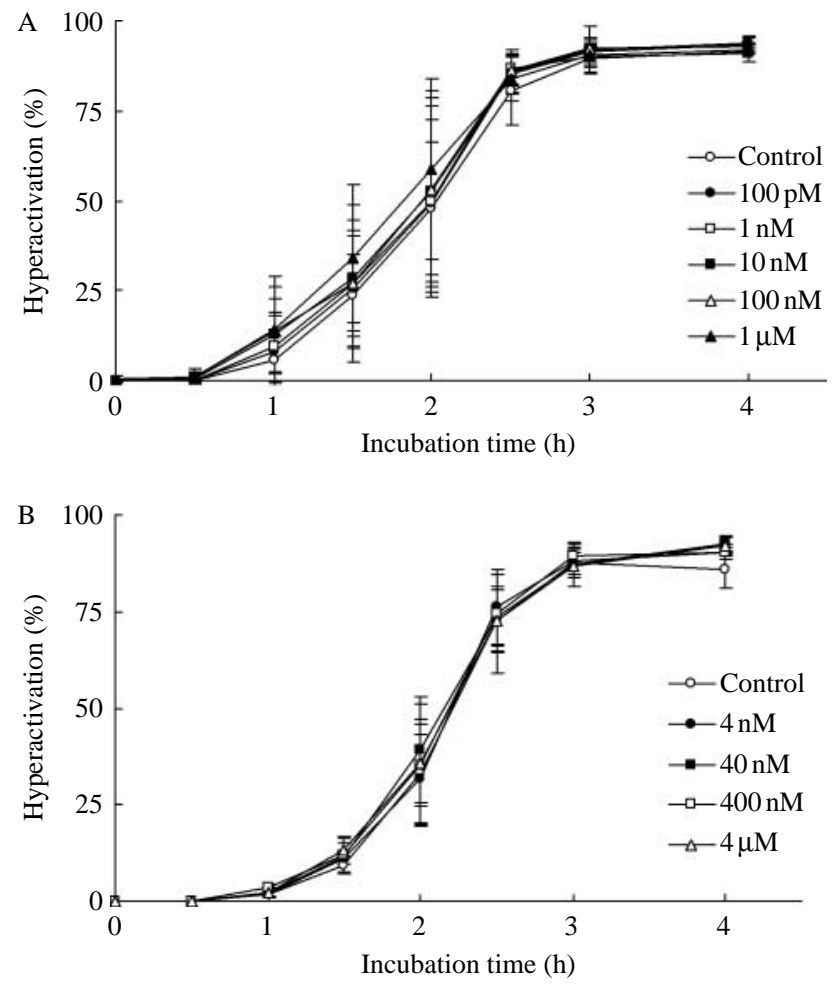

Figure 3 Effects of PPP3 inhibitors on sperm hyperactivation. (A) Time- and dose-dependent changes in sperm hyperactivation with deltamethrin (mean \pm s.D., $n=4$ ). Sperm were incubated in modified TALP medium (control; open circles) or supplemented with $100 \mathrm{pM}$ (closed circles), $1 \mathrm{nM}$ (open squares), $10 \mathrm{nM}$ (closed squares), $100 \mathrm{nM}$ (open triangles), and $1 \mu \mathrm{M}$ (closed triangles) deltamethrin. (B) Time- and dose-dependent changes in sperm hyperactivation with fenvalerate (mean \pm s.D., $n=4$ ). Sperm were incubated in modified TALP medium (control; open circles) or supplemented with $4 \mathrm{nM}$ (closed circles), $40 \mathrm{nM}$ (open squares), $400 \mathrm{nM}$ (closed squares), and $4 \mu \mathrm{M}$ (open triangles) fenvalerate.

no effect on hyperactivation was observed (Fig. 3A). In addition, $4 \mathrm{nM}$ to $4 \mu \mathrm{M}$ fenvalerate had no effect on hyperactivation (Fig. 3B). As for the percentage of motile sperm, they also did not exert an effect (data not shown).

\section{Status of activities of PPP1CA and PPP2 during sperm hyperactivation}

In many cases, enzyme activities are thought to be regulated by post-translational modifications by other enzymes such as phosphorylation, dephosphorylation, and methylation. Activities of PPP1CA and PPP2 are negatively regulated by the phosphorylation of PPP1CA and PPP2 (Chen et al. 1992, 1994, Guo \& Damuni 1993, Kwon et al. 1997). Activity of PPP1CA was inhibited by threonine phosphorylation (Kwon et al. 1997). As shown in Fig. 4, several phosphoprotein bands were detected using anti-phospho-PPP1CA (Thr-320) antibody. But one of them corresponded to PPP1CA. As shown in Fig. 4C, PPP1CA was phosphorylated at incubation for $0,0.5,1$, and $2 \mathrm{~h}$. Interestingly, PPP1CA was dephosphorylated at incubation for 3 and $4 \mathrm{~h}$. Therefore, it seems that PPP1CA is inactivated by phosphorylation during hyperactivation, and is activated by dephosphorylation in hyperactivated sperm.

On the other hand, PPP2 is inactivated by tyrosine phosphorylation (Chen et al. 1992, 1994, Guo \& Damuni 1993). As shown in Fig. 5, tyrosine phosphorylation corresponding to PPP2 was detected in the urea extracts. Tyrosine phosphorylation of PPP2 did not occur at incubation for $0 \mathrm{~h}$ (Fig. 5C, lane a), but it occurred at incubation for $0.5,1,2,3$, and $4 \mathrm{~h}$ (Fig. 5C, lanes b-f). Therefore, it seems that PPP2 was activated in activated sperm at incubation for $0 \mathrm{~h}$, and was inactivated by phosphorylation during hyperactivation and in hyperactivated sperm.

\section{Effects of inhibition of PPP2 on sperm protein tyrosine phosphorylation}

Si \& Okuno (1999b) reported that high concentrations of okadaic acid and calyculin A significantly enhanced $80 \mathrm{kDa}$ tyrosine phosphorylation. In our previous study (Fujinoki et al. 2006), we could detect four tyrosine phosphorylations, which were designated pY80u, pY80ut, pY85u, and pY85ut, in hamster sperm. Because these four proteins were phosphorylated at tyrosine residues during hyperactivation, we examined the effects of low concentrations of okadaic acid (Fig. 6) and calyculin A (Fig. 7) on tyrosine phosphorylation.

As shown in Figs $6 \mathrm{~A}$ and $\mathrm{F}$ and $7 \mathrm{~A}$ and $\mathrm{F}$, tyrosine phosphorylation of pY80u, pY80ut, pY85u, and pY85ut was detected in both the urea extracts and the ureathiourea extracts. Reactivity increased in a timedependent manner (Figs $6 \mathrm{~K}-\mathrm{N}$ and $7 \mathrm{~K}-\mathrm{N}$ ). When $0.1 \mathrm{nM}$ okadaic acid was added to mTALP medium, it was not enhanced (Fig. 6B, G, and $\mathrm{K}-\mathrm{N}$ ). When 10 and $50 \mathrm{nM}$ okadaic acid were added to the mTALP medium,

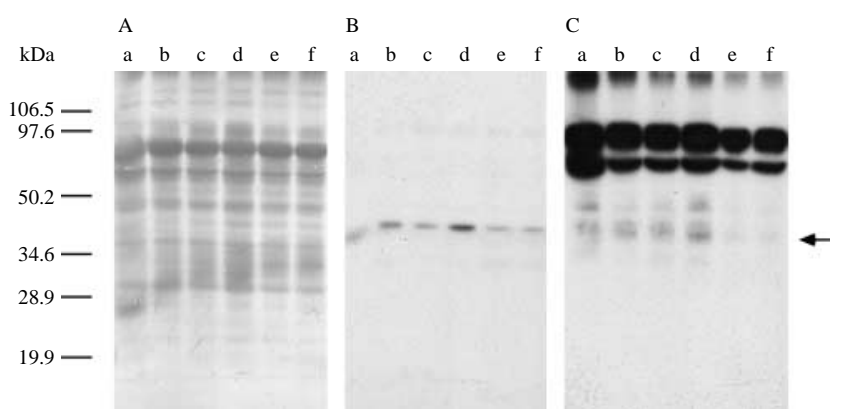

Figure 4 Phosphorylation of PPP1CA during hyperactivation. Twentymicroliter samples were applied for SDS-PAGE of the urea extracts. In (A), blotting membrane stained by CBB is shown. In (B), detection of PPP1CA using anti-PPP1CA antibody (1:1000 dilution) is shown. In (C), detection of phosphorylated PPP1CA using anti-phospho-PPP1CA (Thr-320) antibody (1:1000 dilution) is shown. Lanes a, b, c, d, e, and $f$ indicate $0,0.5,1,2,3$, and $4 \mathrm{~h}$ respectively. Arrow indicates bands of PPP1CA. Other bands of western blotting in (C) were nonspecific. Numbers on the left side of lane a indicate the molecular weights of the standards. 


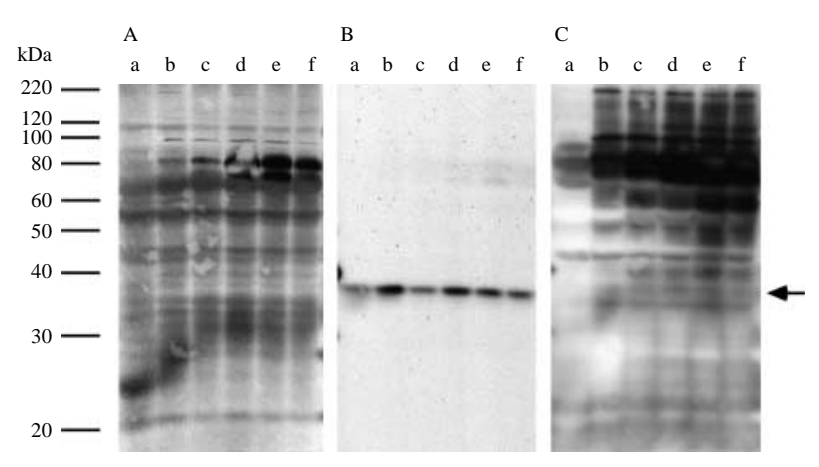

Figure 5 Phosphorylation of PPP2 during hyperactivation. Twentymicroliter samples were applied for SDS-PAGE of the urea extracts. In (A), blotting membrane stained by CBB is shown. In (B), detection of PPP2 using anti-PPP2 C subunit antibody (1:1000 dilution) is shown. In $(C)$, detection of tyrosine phosphorylation using anti-phosphotyrosine MAB (1:1000 dilution) is shown. Lanes $a, b, c, d$, e, and f indicate 0, 0.5, $1,2,3$, and $4 \mathrm{~h}$ respectively. Arrow indicates bands of PPP2. Numbers on the left side of lane a indicate the molecular weights of the standards.

tyrosine phosphorylation of pY80u and pY85u obtained from the urea extracts was not enhanced (Fig. 6C, D, H, I, $\mathrm{K}$, and $\mathrm{L}$ ). But tyrosine phosphorylation of pY80ut and pY85ut obtained from the urea-thiourea extracts was significantly enhanced after incubation for 2, 3, and $4 \mathrm{~h}$ compared with the control and $0.1 \mathrm{nM}$ okadaic acid (Fig. 6C, D, H, I, M, and N). When $500 \mathrm{nM}$ okadaic acid was added to the mTALP medium, tyrosine phosphorylation of pY80u and pY85u obtained from the urea extracts was also not enhanced (Fig. 6E, J-L). But tyrosine phosphorylation of pY85ut obtained from the ureathiourea extracts was significantly enhanced after incubation for $0.5 \mathrm{~h}$ (versus control, and 0.1, 10, and $50 \mathrm{nM}$ okadaic acid), $1 \mathrm{~h}$ (versus control, and 0.1, 10, and $50 \mathrm{nM}$ okadaic acid), $2 \mathrm{~h}$ (versus control and $0.1 \mathrm{nM}$ okadaic acid), $3 \mathrm{~h}$ (versus control and $0.1 \mathrm{nM}$ okadaic acid), and $4 \mathrm{~h}$ (versus control and $0.1 \mathrm{nM}$ okadaic acid; Fig. 6E, J, and M). Additionally, tyrosine phosphorylation of pY80ut obtained from the urea-thiourea extracts was significantly enhanced after incubation for $1 \mathrm{~h}$ (versus control, and 0.1 and $10 \mathrm{nM}$ okadaic acid), $2 \mathrm{~h}$ (versus control and $0.1 \mathrm{nM}$ okadaic acid), $3 \mathrm{~h}$ (versus control and $0.1 \mathrm{nM}$ okadaic acid), and $4 \mathrm{~h}$ (versus control and $0.1 \mathrm{nM}$ okadaic acid; Fig. $6 \mathrm{E}, \mathrm{J}$, and N).

On the other hand, $0.5,2$, and $50 \mathrm{nM}$ calyculin A significantly enhanced tyrosine phosphorylation of pY85u obtained from the urea extracts after incubation for 0.5 and $1 \mathrm{~h}$ compared with the control (Fig. 7B-D, G-I, and K). They significantly enhanced tyrosine phosphorylation of pY80u obtained from the urea extracts after incubation for $1 \mathrm{~h}$ compared with the control (Fig. 7B-D, G-I, and L). Moreover, they significantly enhanced tyrosine phosphorylation of pY85ut obtained from the urea-thiourea extracts after incubation for 1 and $2 \mathrm{~h}$ compared with the control (Fig. 7B-D, G-I, and M). But they did not enhance tyrosine phosphorylation of pY80ut obtained from the urea-thiourea extracts (Fig. 7B-D, G-I, and N). Then, $500 \mathrm{nM}$ calyculin A significantly enhanced tyrosine phosphorylation of pY85u obtained from the urea extracts after incubation for $0.5,1$, and $2 \mathrm{~h}$ compared with the control (Fig. 7E, J, and K). It also enhanced tyrosine phosphorylation of pY80u obtained from the urea extracts after incubation for $1 \mathrm{~h}$ compared with the control (Fig. 7E, J, and L). Moreover, it significantly enhanced tyrosine phosphorylation of pY85ut obtained from the urea-thiourea extracts after incubation for 1 and $2 \mathrm{~h}$ compared with the control (Fig. 7E, J, and M). It also enhanced tyrosine phosphorylation of pY80ut obtained from the urea-thiourea extracts after incubation for $2 \mathrm{~h}$ compared with the control (Fig. 7E, J, and N).

\section{Discussion}

Hyperactivation is the change of sperm flagellar movement that occurs during capacitation, and it is regulated through protein phosphorylation signals (Morisawa 1994, Yanagimachi 1994). In protein phosphorylation signalregulated hyperactivation, $80 \mathrm{kDa}$ tyrosine phosphorylations are important events (Visconti et al. 1995, 1998, 1999, Visconti \& Kopf 1998, Si \& Okuno 1999b, Fujinoki et al. 2001b, 2006, Jha \& Shivaji 2001, Marín-Briggiler et al. 2005), and one of them is identified as AKAP (Jha \& Shivaji 2002a). It has been suggested that $80 \mathrm{kDa}$ tyrosine phosphorylation is regulated by cAMP signals (Visconti et al. 1999), calcium/calmodulin signals (Carrera et al. 1996), and PPP1/PPP2 (Si \& Okuno 1999b).

Several studies have reported that PPP1CC2 is involved in the regulation of motility activation and hyperactivation in mammalian sperm (Smith et al. 1996, Huang et al. 2005, Chakrabarti et al. 2007, Goto \& Harayama 2009). On the other hand, it has been reported that PPP3 is also associated with the regulation of sperm motility and acrosome reaction (Tash et al. 1988, Tash \& Bracho 1994, Ashizawa et al. 2004). In the present study, we have suggested that hamster sperm have PPP1CA, PPP1CC, PPP2, and PPP3 (see Fig. 1).

Previously, Si \& Okuno (1999b) reported that over $80 \%$ of the sperm had become fully hyperactivated within 40 min when $5 \mu \mathrm{M}$ okadaic acid and $2 \mu \mathrm{M}$ calyculin A were added to the mTALP medium. However, $5 \mu \mathrm{M}$ okadaic acid and $2 \mu \mathrm{M}$ calyculin A were much higher than the IC50 concentration of these inhibitors. Therefore, in the present experiment, we have shown that the IC50 concentration of okadaic acid, calyculin A, and tautomycin significantly enhanced sperm hyperactivation (see Fig. 2), although enhancement of hyperactivation differed from the results reported by Si \& Okuno (1999b).

Okadaic acid, calyculin A, and tautomycin are inhibitors of PPP1 and PPP2 (Hardie 1993). Okadaic acid is a highly specific inhibitor of PPP2, and has 100-fold specificity against PPP2 rather than against 


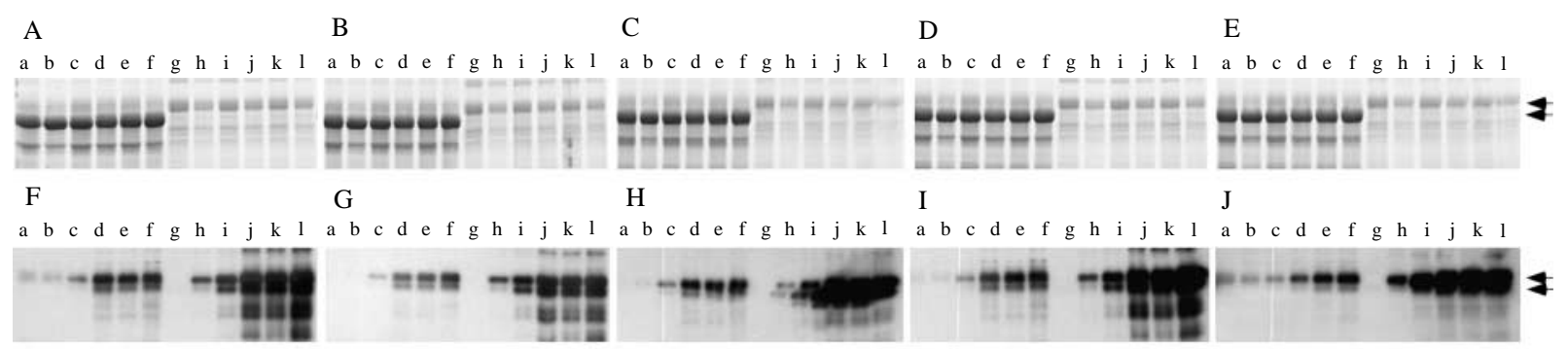

$\mathrm{K}$

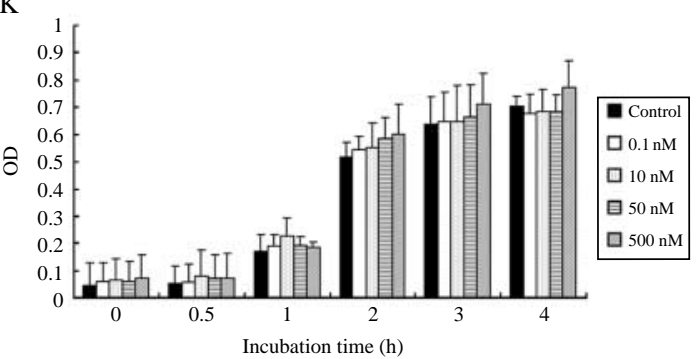

$\mathrm{M}$

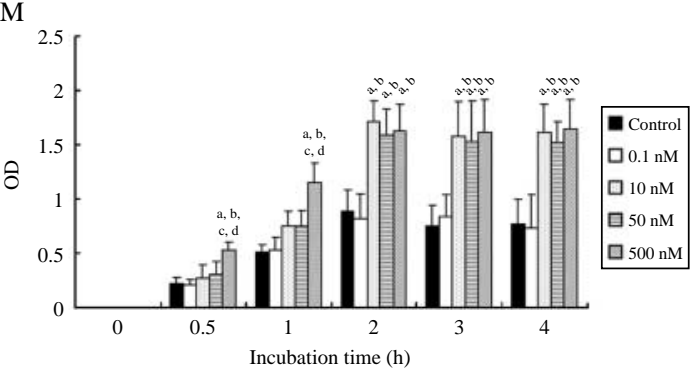

L

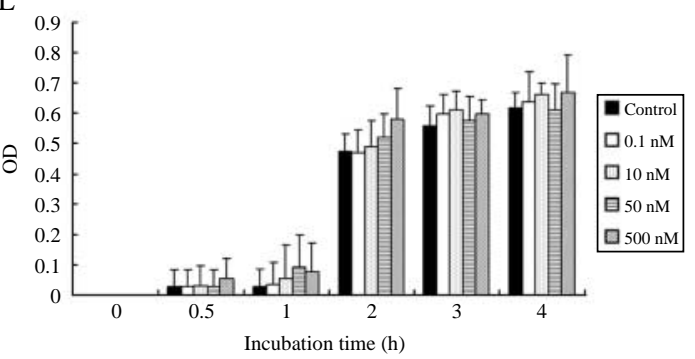

$\mathrm{N}$

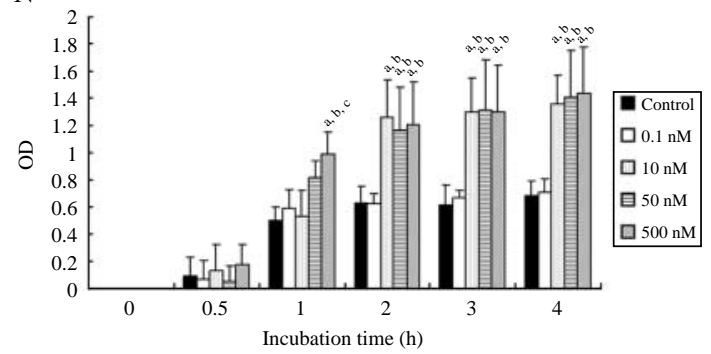

Figure 6 Effects of okadaic acid on time-dependent protein tyrosine phosphorylation during hyperactivation. Sperm were incubated in modified TALP medium alone (A and F) or in the presence of $0.1 \mathrm{nM}$ (B and $\mathrm{G}), 10 \mathrm{nM}(\mathrm{C}$ and $\mathrm{H}), 50 \mathrm{nM}$ (D and I), and $500 \mathrm{nM}$ (E and J) okadaic acid. Photographs A-E show gels stained by CBB, and photographs F-J show western blotting using anti-phosphotyrosine MAB (1:1000 dilution). In SDSPAGE for CBB stain, $10-\mu \mathrm{l}$ samples were applied. On the other hand, $5-\mu \mathrm{l}$ samples were applied in SDS-PAGE for western blotting. Lanes a-f show western blotting of the urea extracts, and lanes g-l show western blotting of the urea-thiourea extracts. Lanes a and $g$, lanes $b$ and $h$, lanes $\mathrm{c}$ and $\mathrm{i}$, lanes $\mathrm{d}$ and $\mathrm{j}$, lanes e and $\mathrm{k}$, and lanes $\mathrm{f}$ and $\mathrm{I}$ indicate $0,0.5,1,2,3$, and $4 \mathrm{~h}$ respectively. Arrows indicate 80 and $85 \mathrm{kDa}$ tyrosine phosphoproteins. Tyrosine phosphorylations of 80 and $85 \mathrm{kDa}$ obtained from the urea extracts correspond to pY80u and pY85u described previously (Fujinoki et al. 2006). On the other hand, 80 and $85 \mathrm{kDa}$ tyrosine phosphorylations obtained from the urea-thiourea extracts correspond to pY80ut and pY85ut described previously (Fujinoki et al. 2006). Tyrosine phosphorylations of pY85u (K) and pY80u (L) obtained from the urea extracts and of pY85ut (M) and pY80ut (N) obtained from the urea-thiourea extracts were analyzed using a densitometer. ' $a$ ' indicates significant differences compared with the control $(P<0.05)$; ' $b$ ' indicates significant differences compared with $0.1 \mathrm{nM}$ okadaic acid $(P<0.05)$; ' $C^{\prime}$ indicates significant differences compared with $10 \mathrm{nM}$ okadaic acid $(P<0.05)$; and ' $\mathrm{d}$ ' indicates significant differences compared with $50 \mathrm{nM}$ okadaic acid $(P<0.05)$.

PPP1. Calyculin A is a less specific inhibitor of PPP2, and has fourfold specificity against PPP2 rather than against PPP1. Calyculin A sometimes inhibits PPP1 rather than PPP2 in an intact cell. Tautomycin is a low specificity inhibitor of PPP1, and has tenfold specificity against PPP1 rather than against PPP2. Because these inhibitors are fat soluble and enter the cell easily, PPPs associated with functions are able to be reasoned by comparison among the effects of inhibitors (Hardie 1993). By understanding the differences in their IC50 values against PPP1 and PPP2, we examined which PPPs are associated with the regulation of hyperactivation (see Fig. 2). Sperm hyperactivation was significantly enhanced when only PPP2, at least, was inhibited by okadaic acid and calyculin A, although we could not show which PPPs were associated with the regulation of hyperactivation when we used tautomycin. On the other hand, it has been suggested that PPP3 is also associated with the regulation of sperm function (Tash et al. 1988, Tash \& Bracho 1994, Ashizawa et al. 2004). However, inhibitors of PPP3 had no effect on sperm hyperactivation (see Fig. 3).

It is widely accepted that tyrosine phosphorylation is closely associated with the regulation of hyperactivation (Si \& Okuno 1999b, Fujinoki et al. 2001b, 2006, Jha \& Shivaji 2001, Marín-Briggiler et al. 2005). In our previous studies (Fujinoki et al. 2006), four tyrosine phosphorylations, namely pY80u, pY80ut, pY85u, and pY85ut, were significantly increased during sperm hyperactivation. Additionally, these tyrosine 


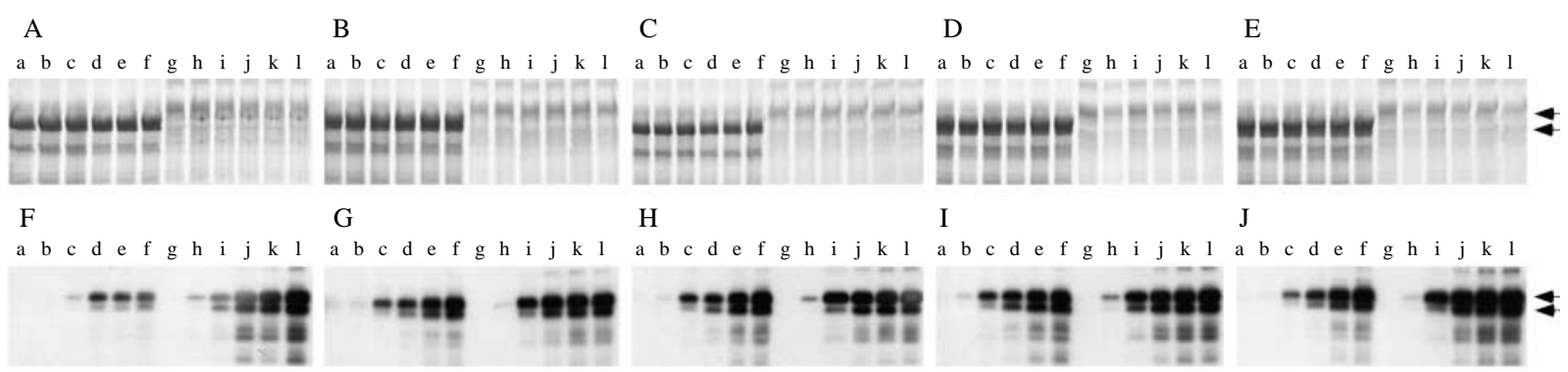

$\mathrm{K}$

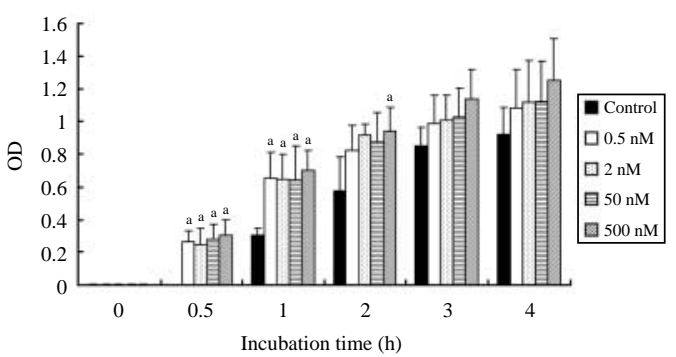

M

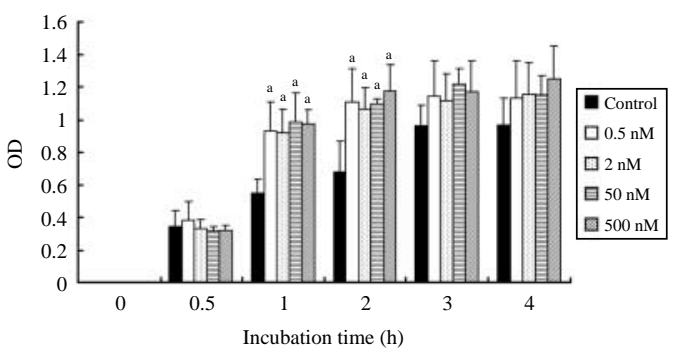

$\mathrm{L}$

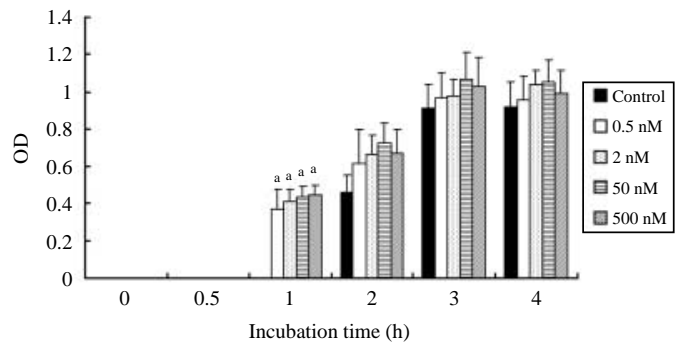

$\mathrm{N}$

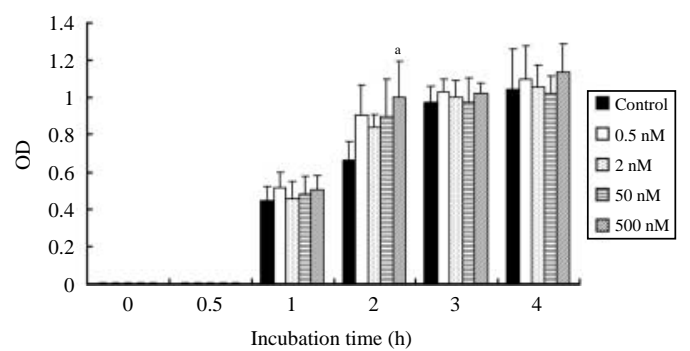

Figure 7 Effects of calyculin A on time-dependent protein tyrosine phosphorylation during hyperactivation. Sperm were incubated in modified TALP medium alone (A and F) or in the presence of $0.5 \mathrm{nM}$ (B and G), $2 \mathrm{nM}(\mathrm{C}$ and $\mathrm{H}), 50 \mathrm{nM}$ (D and I), and $500 \mathrm{nM}$ (E and J) calyculin A. Photographs A-E show gels stained by CBB, and photographs F-J show western blotting using anti-phosphotyrosine MAB (1:1000 dilution). In SDS-PAGE for CBB stain, $10-\mu \mathrm{l}$ samples were applied. On the other hand, $5-\mu \mathrm{l}$ samples were applied in SDS-PAGE for western blotting. Lanes a- $\mathrm{f}$ show western blotting of the urea extracts, and lanes g-l show western blotting of the urea-thiourea extracts. Lanes a and g, lanes b and $\mathrm{h}$, lanes $\mathrm{c}$ and $\mathrm{i}$, lanes $\mathrm{d}$ and $\mathrm{j}$, lanes $\mathrm{e}$ and $\mathrm{k}$, and lanes $\mathrm{f}$ and $\mathrm{I}$ indicate $0,0.5,1,2,3$, and $4 \mathrm{~h}$ respectively. Arrows indicate 80 and $85 \mathrm{kDa}$ tyrosine phosphoproteins. Tyrosine phosphorylations of 80 and $85 \mathrm{kDa}$ obtained from the urea extracts correspond to pY80u and pY85u described previously (Fujinoki et al. 2006). On the other hand, 80 and $85 \mathrm{kDa}$ tyrosine phosphorylations obtained from the urea-thiourea extracts correspond to pY80ut and pY85ut described previously (Fujinoki et al. 2006). pY85u (K) and pY80u (L) obtained from the urea extracts, and pY85ut (M) and pY80ut (N) obtained from the ureathiourea extracts were analyzed using a densitometer. ' $a$ ' indicates significant differences compared with the control $(P<0.05)$.

phosphorylations were significantly enhanced when hyperactivation was enhanced by supplying progesterone (Noguchi et al. 2008). Although protein tyrosine kinase was found in mammalian sperm (Uma Devi et al. 2000), no evidence suggests that it is present during tyrosine phosphorylation associated with the regulation of hyperactivation. On the other hand, it was suggested that cAMP was associated with the regulation of hyperactivation and tyrosine phosphorylation (Visconti \& Kopf 1998, Visconti et al. 1998, 1999). Moreover, cAMP-dependent tyrosine phosphorylation was also detected (Morisawa 1994, Fujinoki et al. 2001b). Because cAMP-dependent protein kinase is generally a serine/threonine kinase, it has been proposed that spermatozoa have a cAMP-dependent tyrosine kinase or a tyrosine kinase regulated by CAMPdependent protein kinase. Recently, several studies have suggested that serine/threonine phosphorylation is associated with the regulation of hyperactivation (Naz 1999, Jha \& Shivaji 2002b, Fujinoki et al. 2004, 2006). Serine/threonine phosphorylation occurred before tyrosine phosphorylation occurred (Fujinoki et al. 2006). Therefore, it seems that tyrosine phosphorylation is generally regulated by serine/threonine phosphorylation. On the other hand, serine/threonine phosphorylation of a $10 \mathrm{kDa}$ protein occurred during hyperactivation after it was phosphorylated at the tyrosine residues (Fujinoki et al. 2004). Moreover, tyrosine phosphorylation of the $10 \mathrm{kDa}$ protein occurred in a cAMP-dependent manner when hamster spermatozoa were activated (Fujinoki et al. 2001 b). Thus, serine/ threonine phosphorylation partially occurred downstream of tyrosine phosphorylation during sperm hyperactivation. 
Si \& Okuno (1999b) also reported that $5 \mu \mathrm{M}$ okadaic acid and $2 \mu \mathrm{M}$ calyculin A significantly enhanced $80 \mathrm{kDa}$ tyrosine phosphorylation. In the present experiment, however, $0.1 \mathrm{nM}$ okadaic acid, which is IC50 value of PPP2, did not enhance four tyrosine phosphorylations, such as $80 \mathrm{u}, 85 \mathrm{u}, 80 \mathrm{ut}$, and $85 \mathrm{ut}$, at all (see Fig. 6). Moreover, 10, 50, and $500 \mathrm{nM}$ okadaic acid enhanced and/or increased two tyrosine phosphorylations obtained from the urea-thiourea extracts such as 80ut and 85ut, although they did not enhance and/or increase two tyrosine phosphorylations obtained from the urea extracts such as $80 u$ and $85 u$. In contrast, calyculin A enhanced and/or increased four tyrosine phosphorylations after incubation for $0.5,1$, and $2 \mathrm{~h}$ (see Fig. 7). The results obtained through okadaic acid suggested that enhancement of hyperactivation by inhibition of PPP2 did not depend on the enhancement of tyrosine phosphorylation. But the results obtained through calyculin A suggested that enhancement of hyperactivation depends on the enhancement of tyrosine phosphorylation. When IC50 values of PPP1 and PPP2 are compared between okadaic acid and calyculin A, differences of okadaic acid are very large (100-fold), but those of calyculin A are very small (fourfold). Therefore, $0.5 \mathrm{nM}$ calyculin A may slightly suppress both PPP1 and PPP2. And then, $10 \mathrm{nM}$ okadaic acid is the IC50 value of PPP1, and may suppress both PPP1 and PPP2. So, it seems that tyrosine phosphorylation was associated with the enhancement of hyperactivation when PPP1 or both PPP1 and PPP2 are inhibited. From the results obtained through okadaic acid and calyculin A (see Figs 2, 6, and 7 ), it is likely that hyperactivation is enhanced by inhibition of PPP2 in a tyrosine phosphorylationindependent manner. And then, inhibition of PPP1 or both PPP1 and PPP2 enhanced and/or increased hyperactivation and tyrosine phosphorylation. Therefore, the question remains whether PPP1 and PPP2 suppress sperm hyperactivation. Previous studies suggested that PPP1CC2 was phosphorylated with motility activation and/or hyperactivation in mouse sperm (Smith et al. 1996, Huang et al. 2005, Chakrabarti et al. 2007, Goto \& Harayama 2009). In two of these studies (Huang et al. 2005, Goto \& Harayama 2009), phosphorylation of PPP1CC2 was examined using antiphospho-PPP1CA antiserum. At the same time, the authors described that anti-phospho-PPP1CA antiserum might cross-react with phospho-PPP1CC2 (Huang et al. 2005, Goto \& Harayama 2009). PPP1CA is negatively regulated by threonine phosphorylation (Kwon et al. 1997). In the present study (see Fig. 4), PPP1CA was phosphorylated at threonine residues before and during hyperactivation, and was dephosphorylated in hyperactivated sperm. Therefore, it seems that PPP1CA is inactive when sperm change from activation to hyperactivation. We could not examine phosphorylation of PPP1CC because we could not obtain anti-phospho-PPP1CC antiserum. To examine phosphorylation of PPP1CA, we purchased anti-phospho-PPP1CA antibody from Cell Signaling Technology (Tokyo, Japan). In the explanatory leaflet, it is described that the anti-phospho-PPP1CA antibody may cross-react with PPP1CC, although this antibody is basically phospho-PPP1CA specific. Goto \& Harayama (2009) used this anti-phospho-PPP1CA antibody purchased from Cell Signaling Technology to examine phosphorylation of PPP1CC in mouse sperm. Huang et al. (2005) also prepared antiserum against the same epitope as this anti-phospho-PPP1CA antibody, and examined phosphorylation of PPP1CC2. Although they described that anti-phospho-PPP1CA antiserum might cross-react with phospho-PPP1CC (Huang et al. 2005, Goto \& Harayama 2009), we could not detect PPP1CC in hamster sperm using this anti-phospho-PPP1CA antibody purchased from Cell Signaling Technology (data not shown).

Activity of PPP2 is negatively regulated by tyrosine phosphorylation (Chen et al. 1992, 1994, Guo \& Damuni 1993). In the present study, PPP2 was phosphorylated at tyrosine residues during hyperactivation and in hyperactivated sperm (see Fig. 5). Since PPP2 was not phosphorylated before the sperm began to be hyperactivated, it is likely that they begin to be hyperactivated by inactivation of PPP2.

The regulatory mechanism of hyperactivation is not yet understood by us. But we suggest that sperm were hyperactivated by inactivation of PPP2 in the present study. Furthermore, tyrosine phosphorylations of 80 and $85 \mathrm{kDa}$ proteins were not associated with the regulation of hyperactivation by inactivation of PPP2, although they were enhanced/increased by inhibition of PPP1. Moreover, it was also suggested that PPP1CA was inactive during hyperactivation, and was active on hyperactivation. On the other hand, the regulation of hyperactivation is associated with several types of protein kinases (Morisawa 1994, Yanagimachi 1994, Fujinoki 2009). In future studies, we plan to examine the relationship between protein kinases and protein phosphatases, and between serine/threonine phosphorylations and dephosphorylations on sperm hyperactivation.

\section{Materials and Methods}

\section{Reagents}

Anti-phosphotyrosine MAB (PT-66) was purchased from Sigma Chemical Company. Anti-PPP1CA antibody, anti-phosphoPPP1CA (Thr-320) antibody, anti-PPP2 C subunit antibody, and anti-Pan-calcineurin A antibody were purchased from Cell Signaling Technology Japan, K.K. Anti-PPP1CB antibody and anti-PPP1CC antibody were purchased from Santa Cruz Biotechnology, Inc (Santa Cruz, CA, USA). Okadaic acid, calyculin A, tautomycin, deltamethrin, and fenvalerate were purchased from Calbiochem Corporation (La Jolla, CA, USA). PVDF membrane was purchased from Millipore (Bedford, MA, USA). ECL plus kit and hyperfilm for ECL were purchased from 
Amersham Biosciences. Other chemicals were of reagent grade from Wako Pure Chemical Industries (Osaka, Japan). Stock solutions of each inhibitor were prepared in DMSO, and were stored at $-20{ }^{\circ} \mathrm{C}$. In the experiment, inhibitors and controls of these agents had $0.1 \%$ DMSO.

\section{Animals and preparation of hyperactivated sperm}

Sexually mature male golden hamsters (Mesocricetus auratus) were used as experimental animals. Hamsters were housed in accordance with the guidelines of the Dokkyo Medical University and the Laboratory Animal Research Center in Dokkyo Medical University of the care and use of laboratory animals.

Sperm were obtained from the caudal epididymis. Hyperactivated sperm were prepared according to a method described previously with a mTALP medium (Si \& Okuno 1999b). An aliquot of caudal epididymal sperm was placed in a culture dish. Several milliliters of the mTALP medium were then carefully added to the culture dish. The culture dish was incubated for 5 min at $37{ }^{\circ} \mathrm{C}$ to allow sperm to swim up, and was incubated for $4 \mathrm{~h}$ at $37^{\circ} \mathrm{C}$ under $5 \% \mathrm{CO}_{2}$ in air to accomplish hyperactivation.

\section{Measurement of motile sperm and hyperactivated sperm}

Percentage of motile sperm and that of hyperactivated sperm were calculated according to the method described in our previous study (Noguchi et al. 2008). Hamster sperm suspended in mTALP medium were diluted to tenfold of the medium, and placed in a culture plate (35-mm dish). Sperm were recorded on a videotape by CCD camera (Progressive 3CCD, Sony, Tokyo, Japan) attached to a microscope (IX70, Olympus, Tokyo, Japan) with phase contrast illumination and a small $\mathrm{CO}_{2}$ incubator (MI-IBC, Olympus). Each observation was carried out at $37^{\circ} \mathrm{C}$, recorded for $5 \mathrm{~min}$, and analyzed by counting the number of total sperm, motile sperm, and hyperactivated sperm in 30 different fields. Motile sperm that exhibited an asymmetric and whiplash flagellar movement (Fujinoki et al. 2001a) were classified as hyperactivated sperm. Percentage of motile sperm (\%) and that of hyperactivated sperm $(\%)$ were respectively defined as (number of motile sperm/number of total sperm) $\times 100$ and (number of hyperactivated sperm/number of total sperm) $\times 100$.

\section{Preparation of sperm protein extracts}

Sperm proteins were extracted according to the method described in our previous study (Fujinoki et al. 2006). At first, collected sperm that were incubated to be hyperactivated were suspended at $30 \mathrm{mg} s p e r m / \mathrm{ml}$ in a urea solution containing $7 \mathrm{M}$ urea and 10\% 2-mercaptoethanol (2-ME). After pipetting, the suspension was incubated on ice for $10 \mathrm{~min}$. After centrifugation at $15000 \mathrm{~g}$ for $10 \mathrm{~min}$ at $4{ }^{\circ} \mathrm{C}$, the supernatants were used as the urea extracts. The precipitate was resuspended in the same volume of the urea-thiourea solution containing $5 \mathrm{M}$ urea, $1 \mathrm{M}$ thiourea, $10 \% 2-\mathrm{ME}$, and $2 \%$ nonidet P-40. After pipetting, the resuspension was incubated on ice for $10 \mathrm{~min}$. After centrifugation at $15000 \mathrm{~g}$ for $10 \mathrm{~min}$ at $4{ }^{\circ} \mathrm{C}$, the supernatants were used as the urea-thiourea extracts.

\section{SDS-PAGE}

SDS-PAGE was carried out according to the method of Laemmli (1970). The separating gel was $10 \%(\mathrm{w} / \mathrm{v})$ polyacrylamide containing $0.1 \%(\mathrm{w} / \mathrm{v})$ SDS. Mixtures $(1: 1)$ of above extracts and SDS buffer containing 10\% SDS, 10\% 2-ME, 10\% glycerol, $0.01 \%$ bromophenol blue, and $0.5 \mathrm{M}$ Tris- $\mathrm{HCl}(\mathrm{pH} 6.8)$ were used as samples for SDS-PAGE.

\section{Western blotting}

Western blotting was carried out according to the method described by Towbin et al. (1979). After SDS-PAGE, the proteins were electroblotted onto a PVDF membrane. The blotted membrane was blocked with $5 \%(\mathrm{w} / \mathrm{v})$ BSA in Tris-buffered saline (TBS) containing $0.15 \mathrm{M} \mathrm{NaCl}$ and $20 \mathrm{mM}$ Tris- $\mathrm{HCl}(\mathrm{pH}$ 7.4) for $1 \mathrm{~h}$ at $20^{\circ} \mathrm{C}$, and was incubated with the primary antibodies with $5 \%(\mathrm{w} / \mathrm{v}) \mathrm{BSA}$ in TBS for $1 \mathrm{~h}$ at $20^{\circ} \mathrm{C}$. After washing with TBS, it was incubated with secondary antibodies (1:5000 dilution) conjugated to HRP with $5 \%(\mathrm{w} / \mathrm{v}) \mathrm{BSA}$ in TBS. A color reaction was carried out with ECL plus kit. Reactivity of western blotting was measured by means of a densitometer (GS-800 densitometer, Bio-Rad Laboratories), and analyzed using Quantity One Software version 4.6.1 (Bio-Rad Laboratories).

\section{Statistical analysis}

Data were analyzed using Tukey's post-hoc test of ANOVA. Values were considered statistically significant when $P<0.05$.

\section{Declaration of interest}

The authors declare that there is no conflict of interest that could be perceived as prejudicing the impartiality of the research reported.

\section{Funding}

This work was supported by a Grant-in-Aid for Young Scientists (B) from the Ministry of Education, Culture, Sports, Science and Technology of Japan to T Suzuki. (No. 17791134 and 20791159) and M Fujinoki (No. 15790860 and 18791135), and by a Jichi Medical University Young Investigator Award to T Suzuki.

\section{References}

Ashizawa K, Wishart GJ, Ranasinghe ARAH, Katayama S \& Tsuzuki Y 2004 Protein phosphatase-type $2 \mathrm{~B}$ is involved in the regulation of the acrosome reaction but not in the temperature-dependent flagellar movement of fowl spermatozoa. Reproduction 128 783-787.

Austin CR 1952 The capacitation of the mammalian sperm. Nature 170326.

Baker MA, Hetherington L \& Aitken RJ 2006 Identification of pp60c-src as a key PKA-stimulated tyrosine kinase involved in the capacitation and hyperactivation of murine spermatozoa. Journal of Cell Science $\mathbf{1 1 9}$ 3182-3192.

Baker MA, Hetherington L, Curry B \& Aitken RJ 2009 Phosphorylation and consequent stimulation of the tyrosine kinase c-Abl by PKA in mouse spermatozoa; its implications during capacitation. Developmental Biology 333 57-66. 
Barford D, Das AK \& Egloff MP 1998 The structure and mechanism of protein phosphatases: insights into catalysis and regulation. Annual Review of Biophysics and Biomolecular Structure 27 133-164.

Breitbart H 2002 Intracellular calcium regulation in sperm capacitation and acrosomal reaction. Molecular and Cellular Endocrinology 187 139-144.

Carrera A, Moos J, Ning XP, Gerton GL, Tesarik J, Kopf GS \& Moss SB 1996 Regulation of protein tyrosine phosphorylation in human sperm by a calcium/calmodulin-dependent mechanism: identification of A kinase anchoring proteins as major substrates for tyrosine phosphorylation. Developmental Biology 180 284-296.

Ceulemans H \& Bollen M 2004 Functional diversity of protein phosphatase-1, a cellular economizer and reset button. Physiological Reviews 84 1-39.

Chakrabarti R, Cheng L, Puri P, Soler D \& Vijayaraghavan S 2007 Protein phosphatase PP1 gamma 2 in sperm morphogenesis and epididymal initiation of sperm motility. Asian Journal of Andrology 9 445-452.

Chang MC 1951 Fertilizing capacity of spermatozoa deposited into the fallopian tubes. Nature 168 697-698.

Chen J, Martin BL \& Brautigan DL 1992 Regulation of protein serinethreonine phosphatase type-2A by tyrosine phosphorylation. Science 257 1261-1264.

Chen J, Parsons S \& Brautigan DL 1994 Tyrosine phosphorylation of protein phosphatase $2 \mathrm{~A}$ in response to growth stimulation and $\mathrm{V}$-src transformation of fibroblasts. Journal of Biological Chemistry 269 7957-7962.

Fujinoki M 2009 Non-genomic regulation of mammalian sperm hyperactivation. Reproductive Medicine and Biology 8 47-52.

Fujinoki M, Ohtake H \& Okuno M 2001a Serine phosphorylation of flagellar proteins associated with the motility activation of hamster spermatozoa. Biomedical Research 22 45-58.

Fujinoki M, Ohtake H \& Okuno M 2001b Tyrosine phosphorylation and dephosphorylation associated with motility of hamster spermatozoa. Biomedical Research 22 147-155.

Fujinoki M, Ishimoda-Takagi T \& Ohtake H 2004 Serine/threonine phosphorylation associated with hamster sperm hyperactivation. Reproductive Medicine and Biology 3 223-230.

Fujinoki M, Suzuki T, Takayama T, Shibahara H \& Ohtake H 2006 Profiling of proteins phosphorylated or dephosphorylated during hyperactivation via activation on hamster spermatozoa. Reproductive Medicine and Biology 5 123-135.

Furuya S, Endo Y, Oba M, Nozawa S \& Suzuki S 1992 Effects of modulators of protein kinases and phosphatases on mouse sperm capacitation. Journal of Assisted Reproduction and Genetics 9 391-399.

Furuya S, Endo Y, Osumi K, Oba M, Nozawa S \& Suzuki S 1993 Calyculin A, protein phosphatase inhibitor, enhances capacitation of human sperm. Fertility and Sterility 59 216-222.

Goto N \& Harayama H 2009 Calyculin A-sensitive protein phosphatases are involved in maintenance of progressive movement in mouse spermatozoa in vitro by suppression of autophosphorylation of protein kinase A. Journal of Reproduction and Development 55 327-334.

Guo H \& Damuni Z 1993 Autophosphorylation-activated protein kinase phosphorylates and inactivates protein phosphatase 2A. PNAS 90 2500-2504.

Hardie DG 1993 Use of protein phosphatase inhibitors in intact cells. In Protein Phosphorylation, pp 109-119. Ed. DG Hardie. New York, NY: Oxford University Press.

Huang Z, Somanath PR, Chakrabarti R, Eddy EM \& Vijayaraghavan S 2005 Changes in intracellular distribution and activity of protein phosphatase PPP1CC2 and its regulating proteins in spermatozoa lacking AKAP4. Biology of Reproduction 72 384-392.

Jha K \& Shivaji S 2001 Capacitation-associated changes in protein tyrosine phosphorylation, hyperactivation and acrosome reaction in hamster spermatozoa. Andrologia 33 95-104.

Jha K \& Shivaji S 2002a Identification of the major tyrosine phosphorylated protein of capacitated hamster spermatozoa as a homologue of mammalian sperm A kinase anchoring protein. Molecular Reproduction and Development $61258-270$.

Jha K \& Shivaji S $2002 b$ Protein serine and threonine phosphorylation, hyperactivation and acrosome reaction in in vitro capacitated hamster spermatozoa. Molecular Reproduction and Development 63 119-130.

Kwon YG, Lee SY, Choi Y, Greengard P \& Nairn AC 1997 Cell cycledependent phosphorylation of mammalian protein phosphatase 1 by cdc2 kinase. PNAS 94 2168-2173.
Laemmli UK 1970 Cleavage of structural proteins during the assembly of the head of bacteriophage T4. Nature 227 680-685.

Langlais J \& Roberts KD 1985 A molecular membrane model of sperm capacitation and the acrosome reaction of mammalian spermatozoa. Gamete Research 12 183-224.

Marín-Briggiler Cl, Jha KN, Chertihin O, Buffone MG, Herr JC, VazquezLevin MH \& Visconti PE 2005 Evidence of the presence of calcium/calmodulin-dependent protein kinase IV in human sperm and its involvement in motility regulation. Journal of Cell Science $\mathbf{1 1 8}$ 2013-2022.

Morisawa M 1994 Cell signaling mechanisms for sperm motility. Zoological Science 11 647-662.

Naz RK 1999 Involvement of protein serine and threonine phosphorylation in human sperm capacitation. Biology of Reproduction 60 1402-1409.

Noguchi T, Fujinoki M, Kitazawa M \& Inaba N 2008 Regulation of hyperactivation of hamster spermatozoa by progesterone. Reproductive Medicine and Biology 7 63-74.

Okamura N, Tajima Y, Soejima A, Masuda H \& Sugita Y 1985 Sodium bicarbonate in seminal plasma stimulates the motility of mammalian spermatozoa through direct activation of adenylate cyclase. Journal of Biological Chemistry 260 9699-9705.

Si Y \& Okuno M 1999a Regulation of microtubule sliding by a 36-kDa phosphoprotein in hamster sperm flagella. Molecular Reproduction and Development 52 328-334.

Si Y \& Okuno M 1999b Role of tyrosine phosphorylation of flagellar proteins in hamster sperm hyperactivation. Biology of Reproduction 61 240-246.

Smith GD, Wolf DP, Trautman KC, de Cruz e Silva EF, Greengard P \& Vijayaraghavan S 1996 Primate sperm contain protein phosphatase 1, a biochemical mediator of motility. Biology of Reproduction 54 719-727.

Suarez SS \& Ho HC 2003 Hyperactivated motility in sperm. Reproduction in Domestic Animals 38 119-124.

Tash JS \& Bracho GE 1994 Regulation of sperm motility: emerging evidence for a major role for protein phosphatases. Journal of Andrology 15 505-509.

Tash JS, Krinks M, Patel J, Means RL, Klee CB \& Means AR 1988 Identification, characterization, and functional correlation of calmodulin-dependent protein phosphatase in sperm. Journal of Cell Biology 106 1625-1633.

Towbin H, Staehelin T \& Gordon J 1979 Electrophoretic transfer of proteins from polyacrylamide gels to nitrocellulose sheets: procedure and some applications. PNAS 76 4350-4354.

Uma Devi K, Jha K, Patil SB, Padma P \& Shivaji S 2000 Inhibition of motility of hamser spermatozoa by protein tyrosine kinase inhibitors. Andrologia 32 95-106.

Visconti PE \& Kopf GS 1998 Regulation of protein phosphorylation during sperm capacitation. Biology of Reproduction 59 1-6.

Visconti PE, Bailey JL, Moore GD, Pan D, Olds-Clarke P \& Kopf GS 1995 Capacitation of mouse spermatozoa. I. Correlation between the capacitation state and protein tyrosine phosphorylation. Development 121 1129-1137.

Visconti PE, Galantino-Homer H, Moore GD, Bailey JL, Ning X, Fornes M \& Kopf GS 1998 The molecular basis of sperm capacitation. Journal of Andrology 19 242-248.

Visconti PE, Stewart-Savage J, Blasco A, Battaglia L, Miranda P, Kopf GS \& Tezón JG 1999 Roles of bicarbonate, CAMP, and protein tyrosine phosphorylation on capacitation and the spontaneous acrosome reaction of hamster sperm. Biology of Reproduction 61 76-84.

Yanagimachi R 1994 Mammalian fertilization. In The Physiology of Reproduction, vol 2, edn 2, pp 189-317. Eds E Knobil \& JD Neill. New York, NY: Raven Press.

Yudine AI, Gottlieb W \& Meizel S 1988 Ultrastructural studies of the early events of the human sperm acrosome reaction as initiated by human follicular fluid. Gamete Research 20 11-24.

Received 26 August 2008

First decision 29 September 2008

Revised manuscript received 18 January 2010

Accepted 25 February 2010 